\title{
A New Pygmy Seahorse (Pisces: Syngnathidae: Hippocampus) from Lord Howe Island
}

\author{
RUDIE H. KUITER \\ Ichthyology, Museum Victoria, Melbourne Victoria 3001, Australia \\ rudie.kuiter@zoonetics.com·syngnathiformes@zoonetics.com
}

\begin{abstract}
A new species of seahorse, Hippocampus colemani, is described from Lord Howe Island off eastern Australia. It can be distinguished from congeners by the following combined features: very small size (to about $23 \mathrm{~mm}$ in height), very deep trunk (about 60\% in its length), low number of tail rings (27-29) and most distinctly, a single gill opening, placed dorsally behind the head.
\end{abstract}

Kuiter, Rudie H., 2003. A new pygmy seahorse (Pisces: Syngnathidae: Hippocampus) from Lord Howe Island. Records of the Australian Museum 55(2): 113-116.

Seahorses are currently placed in a single genus: Hippocampus (family Syngnathidae). The Australian species were recently revised by Kuiter (2001), who recognized 24 species, two of which are diminutive, reaching less than $50 \mathrm{~mm}$ height. The two are collectively known as pygmy seahorses. These tiny species usually occur at depths of $30 \mathrm{~m}$ or more, but a third pygmy species was discovered at a depth of only $5 \mathrm{~m}$ in the lagoon at Lord Howe Island in the Tasman Sea. A description of the species, based on two specimens, is presented here.

\section{Materials and methods}

Methodology follows that of Kuiter (2001), except specimens were photographed and enlarged 20 times and proportional measurements recorded from the enlarged photos. Radiographs were used to confirm the number of tail rings. Sex was determined on the absence or presence of a pouch, however, in pygmy species this character is not as obvious as in the larger species. In all seahorse species, including pygmy species, the position of the anus in both sexes is at the same horizontal level in relation to the dorsal fin base. All males have a pouch and the anus is positioned further away from the body axis compared to the female. The pouch can look somewhat like a posterior extension of the trunk since the anus is often not obvious, especially when brooding. This is applicable to pygmy seahorses and sex can be determined by the posterior reach of their trunk and pouch combined in relation to the horizontal level with the dorsal-fin base, especially when working with photographs. The specimens are deposited in the Australian Museum, Sydney (AMS).

\section{Hippocampus colemani n.sp.}

Figs. 1, 2

$$
\text { Coleman's Pygmy Seahorse }
$$

Type material. Holotype: AMS I41181-001, height $22.1 \mathrm{~mm}$, female, near Erscott's Hole, lagoon, Lord Howe Island, New South Wales (approximately $32^{\circ} 32.950^{\prime} \mathrm{S} 159^{\circ} 05.080^{\prime} \mathrm{E}$ ), depth $5 \mathrm{~m}$, collected by hand, Neville Coleman, January, 2002. PARATYPE: AMS I41181-002, height $21.4 \mathrm{~mm}$, female, same data as holotype.

Diagnosis. Dorsal-fin rays 12-13; pectoral-fin rays 10; anal fin absent; trunk rings 11; tail rings 27-29; nose ridge well 